\title{
Erratum to: In Situ Phase Evolution of Ni/Ti Reactive Multilayers
}

\author{
A.J. Cavaleiro, A.S. Ramos, R.M.S. Martins, C. Baehtz, M.T. Vieira, and F.M. Braz Fernandes
}

\section{Erratum to: J. of Materi Eng and Perform DOI 10.1007/s11665-014-1072-y}

Please note that the correct spelling of the surname of the fourth author of this article should be Baehtz (rather than Baetz).

The online version of the original article can be found under doi:10.1007/s11665-014-1072-y.

A.J.Cavaleiro, A.S. Ramos, and M.T. Vieira, CEMUC, Department of Mechanical Engineering, University of Coimbra, Coimbra, Portugal; R.M.S. Martins and F.M. Braz fernandes, CENIMAT - I3 N, Materials Science Department, FCT/UNL, Monte de Caparica, Portugal; and C.Baehtz, Institute of Ion Beam Physics and Materials Research, Helmholtz-Zentrum Dresden-Rossendorf (HZDR), Dresden, Germany. Contact e-mails: andre.cavaleiro@dem.uc.pt, sofia.ramos@dem.uc.pt, rmsm@fct.unl.pt, baehtz@esrf.fr, teresa.vieira@dem.uc.pt, and fbf@ fct.unl.pt. 